University of Nebraska - Lincoln

DigitalCommons@University of Nebraska - Lincoln

June 2002

\title{
Chemical Bonds Broken in Latent Tracks of Light lons in Plastic Track Detectors
}

\author{
R. Barillon \\ M. Fromm \\ France,mfromm@utinam.univ-fcomte.fr \\ Robert Katz \\ University of Nebraska-Lincoln, rkatz2@unl.edu
}

Université Louis Pasteur, Institut de Recherches Subatomiques CNRS/IN2P3, 67037 Strasbourg, France

Université de Franche Comté, Laboratoire de Microanalyses Nucléaires, EA473, LRC CEA M07, Besancon,

A. Chambaudet

Université de Franche Comté, Laboratoire de Microanalyses Nucléaires, EA473, LRC CEA M07, Besancon, France

Follow this and additional works at: https://digitalcommons.unl.edu/physicskatz

Part of the Physics Commons

Barillon, R.; Fromm, M.; Katz, Robert; and Chambaudet, A., "Chemical Bonds Broken in Latent Tracks of Light lons in Plastic Track Detectors" (2002). Robert Katz Publications. 133.

https://digitalcommons.unl.edu/physicskatz/133

This Article is brought to you for free and open access by the Research Papers in Physics and Astronomy at DigitalCommons@University of Nebraska - Lincoln. It has been accepted for inclusion in Robert Katz Publications by an authorized administrator of DigitalCommons@University of Nebraska - Lincoln. 
Published in Radiation Protection Dosimetry 99:1-4 (2002), pp. 359-362.

Copyright @ 2002 Nuclear Technology Publishing/Oxford University Press. http://rpd.oxfordjournals.org

\title{
Chemical Bonds Broken in Latent Tracks of Light Ions in Plastic Track Detectors
}

\author{
R. Barillon, ${ }^{1}$ M. Fromm, ${ }^{2}$ R. Katz, ${ }^{3}$ and A. Chambaudet ${ }^{2}$ \\ ${ }^{1}$ Université Louis Pasteur, Institut de Recherches Subatomiques CNRS/IN2P3, 67037 Strasbourg, France \\ ${ }^{2}$ Université de Franche Comté, Laboratoire de Microanalyses Nucléaires, EA473, LRC CEA M07, Besancon, France \\ ${ }^{3}$ University of Nebraska-Lincoln, Lincoln, NE 68588-0111, USA \\ Corresponding author-M. Fromm, email mfromm@utinam.univ-fcomte.fr
}

\begin{abstract}
When a swift ion is slowed down through a plastic detector it creates a latent track. In nuclear track detectors, this latent track can be specifically etched by an appropriate chemical solution. This enlargement process is due to a higher etch velocity $\left(\mathrm{V}_{\mathrm{T}}\right)$ along the ion's path than in the non-damaged part of the detector. The etched track velocity is definitely linked to the damage created by the incoming ion in the detector material. A relationship between the physical parameters of the energy deposition and the variation in this etched track velocity with the ion energy cannot easily be explained. We present here our study on the chemical damage created by several ions in a cellulose nitrate type detector and our first attempt to simulate them by the use of the hit theory.
\end{abstract}

\section{Etched Track Velocity and Physical Parameters}

In previous studies attempts were made to outline the kind of relationship that exists between the measured etched track rate, $\mathrm{V}_{\mathrm{T}}$, and the basic physical parameters of the ion-matter interaction In cellulose nitrate (LR115, Kodak) as well as poly allyl diglycol carbonate (CR-39, Tastrak) irradiated with $\mathrm{MeV}$ alpha or lithium ions, the average radial delta ray dose, the total LET or $\mathrm{REL}_{350}$ do not uniquely describe the experimental $\mathrm{V}_{\mathrm{T}} \mathrm{S}$ [1-3]. (Figure 1)

\section{Chemical Damage and Infra Red Spectroscopy}

The LR115 used in this study is a trademark of Kodak; the detector is $12 \mu \mathrm{m}$ thick. Cellulose nitrate $(\mathrm{CN})$ constitutes $90 \%$ of its weight, the residual $10 \%$ are additives. The degree of $\mathrm{CN}$ nitration used is around 2.3. Each irradiated sample consists of a stack of several LR115 detectors each $12 \mu \mathrm{m}$ thick (from 17 to 32 detectors according to the ion energy). The energy loss in each layer was estimated using the TRIM code [5]. After exposure to known ion fluences in the vacuum, the detectors were analyzed by infrared (FTIR) spectroscopy

Figure 2 presents the cellulose nitrate structure as well as the main modifications observed by infrared spectroscopy [7]. The band at $1160 \mathrm{~cm}^{-1}$ can most likely be attributed to the glycosidic bond (C-O-C) that links two pyranose rings [8]. The band at $1600 \mathrm{~cm}^{-1}$ corresponds to the $\mathrm{O}-\mathrm{NO}_{2}$ bonds, and the one at $1340 \mathrm{~cm}^{-1}$ to the $\mathrm{C}-\mathrm{H}$ bonds.

\section{Chemical Bond Breaking Cross Sections}

Here, it is assumed that the relative decrease in the considered bond ( $\left.\Pi_{\text {bond }}\right)$ can be described by [9]:

$$
\Pi_{\text {bond }}=\exp ^{-\mathrm{oF}}
$$

where $\mathrm{F}$ is the fluence of the incoming ions and $\sigma$ is defined as the global scission cross section corresponding to the final effect observed after chemical equilibrium.

Figures 3 and 4 show the measured scission cross sections plotted against the initial ion energy for boron and carbon ions that were slowed down in the LR115.

In each case the same tendency can be observed: the cross sections decrease from $\mathrm{C}-\mathrm{O}$ bonds to $\mathrm{N}-\mathrm{O}$ and to $\mathrm{C}-\mathrm{H}$ bonds. The scission cross sections increase inversely in relation to the ion energy.

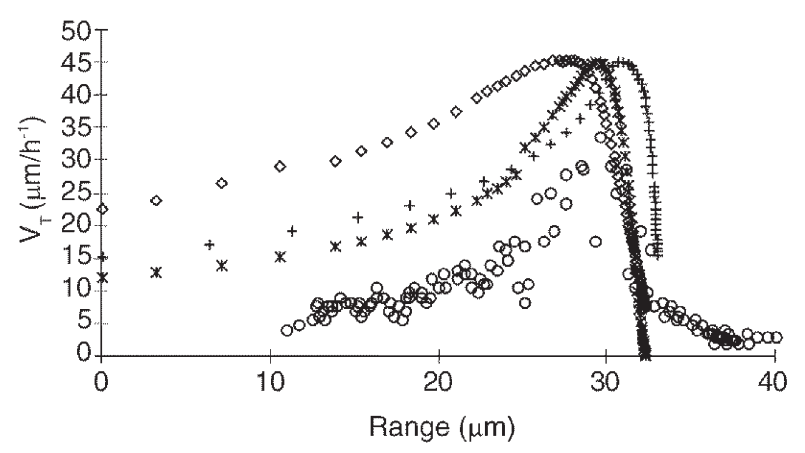

Figure 1. Comparison of the etched track rate $\left(\mathrm{V}_{\mathrm{T}}\right)$ for a $\mathrm{Li}$ ion in (०) CR-39 [3] based on experimental data with, $\left(^{*}\right)$ the average dose from $\delta$ rays within $8 \mathrm{~nm}$ of the ion's path [4], $(\diamond)$ total LET [5] and (+) $\operatorname{REL}_{350}[6]$. 


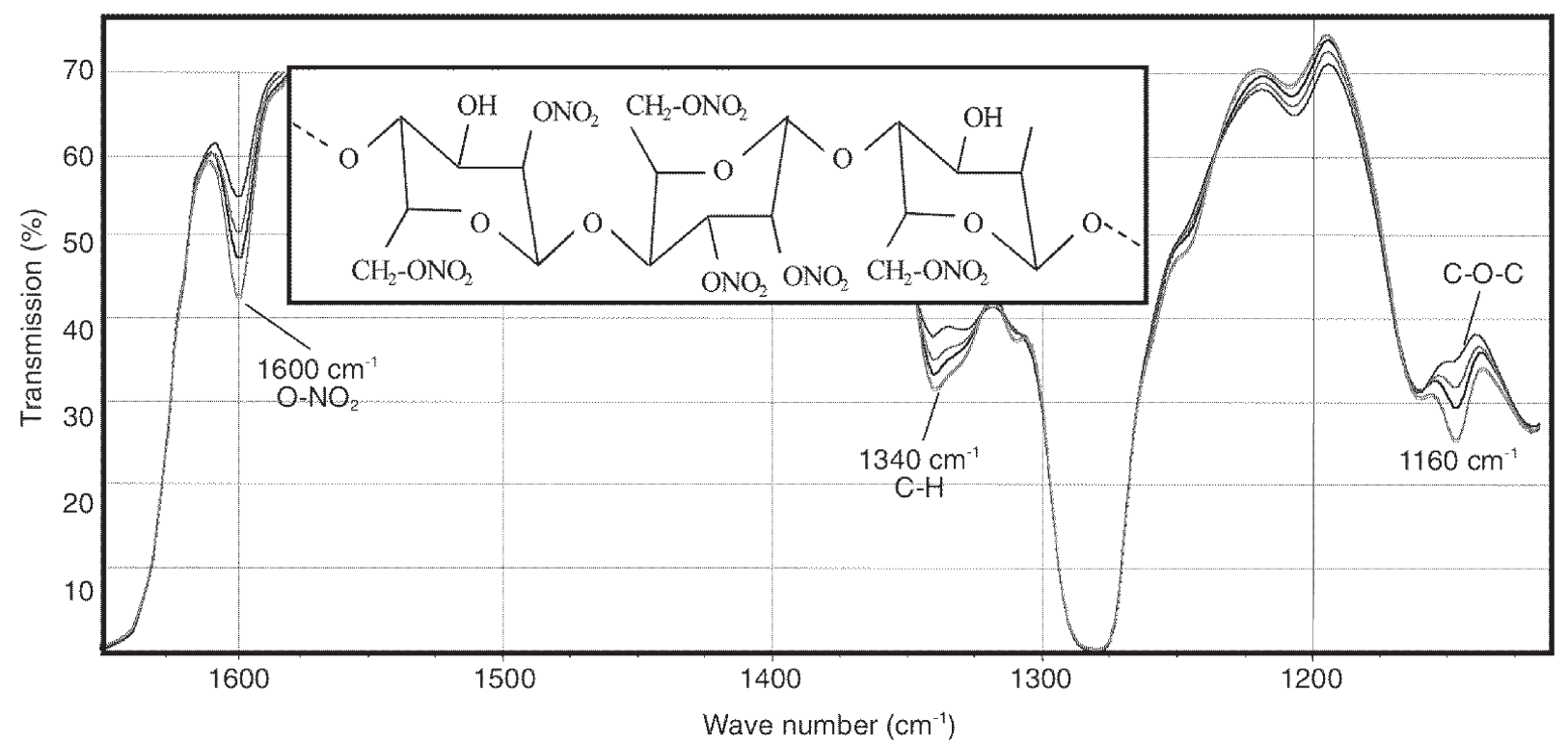

Figure 2. Main modifications (band decreasing) observed by FTIR (transmission mode) during irradiation of a $12 \mu \mathrm{m}$ thick LR115 with ${ }^{241} \mathrm{Am}$.

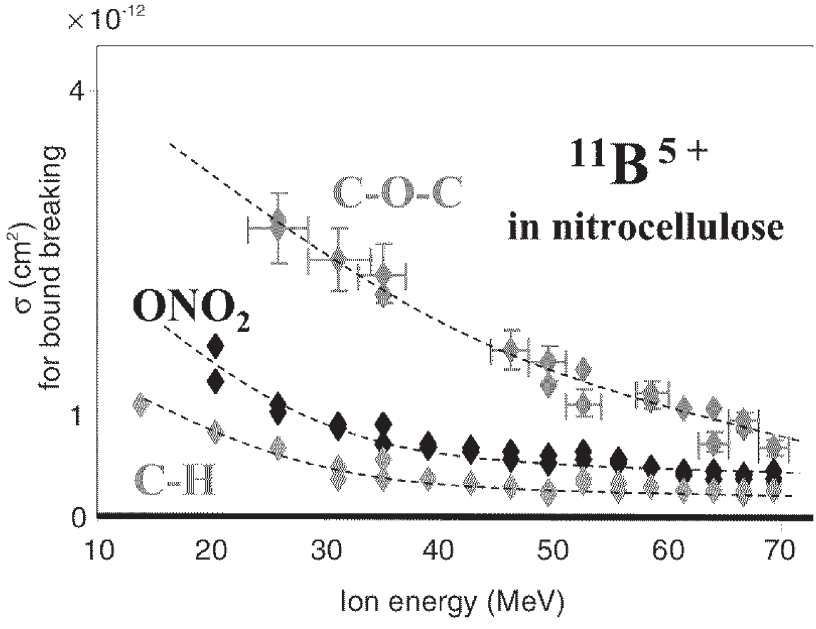

Figure 3. Scission cross sections for ${ }^{11} \mathrm{~B}^{5+}$ in LR115.

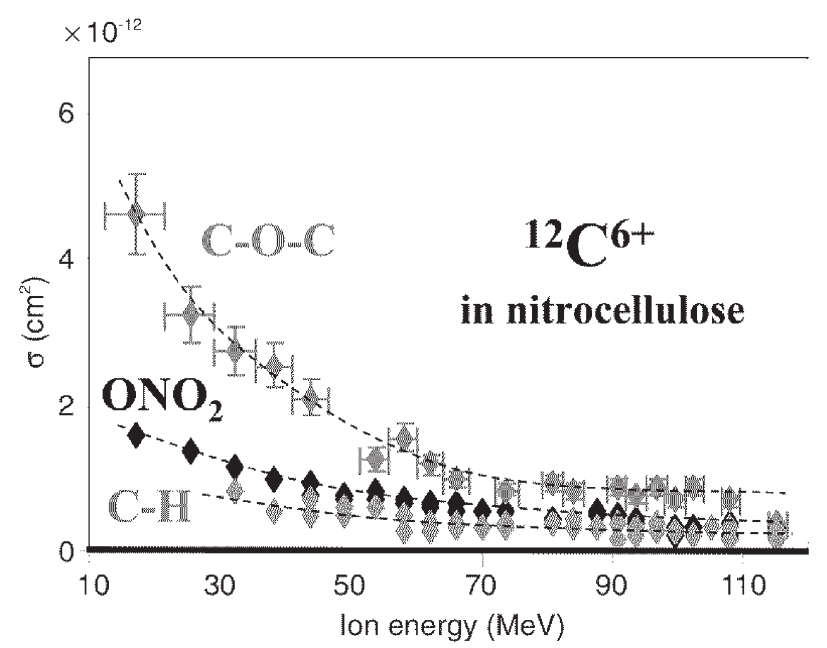

Figure 4. Scission cross sections for ${ }^{12} \mathrm{C}^{6+}$ in LR115

Table 1. Simulated and experimental scission cross sections.

\begin{tabular}{|c|c|c|c|c|c|}
\hline Ion & $\begin{array}{l}\text { Energy } \\
(\mathrm{MeV})\end{array}$ & $\begin{array}{c}\text { Experimental } \\
\quad \sigma_{\mathrm{CO}}\left(\mathrm{cm}^{2}\right)\end{array}$ & $\begin{array}{c}\text { Model } \\
\sigma_{\mathrm{CO}}\left(\mathrm{cm}^{2}\right) \\
\mathrm{m}=1 \\
\mathrm{a}_{0}=0.2 \mathrm{~nm} \\
\mathrm{D}_{0}=2 \times 10^{5} \mathrm{~Gy}\end{array}$ & $\begin{array}{c}\text { Experimental } \\
\sigma_{\mathrm{NO}}\left(\mathrm{cm}^{2}\right)\end{array}$ & $\begin{array}{c}\text { Model } \\
\sigma_{\mathrm{NO}}\left(\mathrm{cm}^{2}\right) \\
\mathrm{m}=1 \\
\mathrm{a}_{0}=0.2 \mathrm{~nm} \\
\mathrm{D}_{0}=3 \times 10^{5} \mathrm{~Gy}\end{array}$ \\
\hline \multirow[t]{2}{*}{${ }^{11} \mathrm{~B}^{5+}$} & 69 & $6.7 \times 10^{-13}$ & $5.5 \times 10^{-13}$ & $3.9 \times 10^{-13}$ & $3.7 \times 10^{-13}$ \\
\hline & 49 & $1.5 \times 10^{-12}$ & $7.0 \times 10^{-13}$ & $5.9 \times 10^{-13}$ & $4.6 \times 10^{-13}$ \\
\hline \multirow[t]{3}{*}{${ }^{12} C^{6+}$} & 102 & $6.7 \times 10^{-13}$ & $9.3 \times 10^{-13}$ & $3.0 \times 10^{-13}$ & $5.8 \times 10^{-13}$ \\
\hline & 80 & $9.5 \times 10^{-13}$ & $1.0 \times 10^{-12}$ & $4.0 \times 10^{-13}$ & $7.4 \times 10^{-13}$ \\
\hline & 17 & $4.6 \times 10^{-12}$ & $2.2 \times 10^{-12}$ & $1.6 \times 10^{-12}$ & $1.5 \times 10^{-12}$ \\
\hline
\end{tabular}




\section{Dose and Chemical Structure}

To try to describe the chemical structure of the latent track, the same approach [10] as proposed by Katz and Pinkerton [11] is developed for the nuclear emulsion response. Thus it is stipulated that the probability $\mathrm{P}$ of breaking a given chemical bond is:

$$
P(r)=\left\{1-\exp -\left[\bar{D}(r) / D_{0}\right]\right\}^{m}
$$

where $\mathrm{m}$ is the number of hits needed to break a bond, $\mathrm{D}_{0}$ the dose at which there is one hit per target and $\overline{\mathrm{D}}(\mathrm{r})$ the average local dose delivered to the bonds at a distance $r$ from the ion's path (deposited by free elections emitted by the incident ion). Such a dose quantity concept is proposed by Miterev [12] in literature describing the relationship between $\mathrm{V}_{\mathrm{T}}$ and the ion parameters. The dose $\overline{\mathrm{D}}(\mathrm{r})$ is calculated using the following simple expression averaged over the target size $\mathrm{a}_{0}[13]$ :

$$
\mathrm{D}(\mathrm{r})=\frac{\mathrm{N} \mathrm{Z} \mathrm{Z}^{2}}{\mathrm{~m} \mathrm{c}^{2} \beta^{2}}\left(\frac{1}{\mathrm{r}^{2}}-\frac{1}{\mathrm{r} . \tau}\right)
$$

This relation gives the dose deposited by the different generations of electrons produced by the incident ion as a function of the distance $r$ from the ion's path, where $\mathrm{N}$ is the number of target electrons per unit volume, e the elementary charge, $\mathrm{m}$ the electron mass, $\mathrm{c}$ the speed of light, $\tau$ the range of the most energetic election from an ion moving at relative speed $\beta$, and $Z$ the effective charge of the ion [14]. More sophisticated solutions for calculating this dose have been proposed more recently [15]. At this stage, however, precision is not sought, but a definition is wanted of the principles of our approach.

Finally, the cross section for bond breaking is expressed by:

$$
\sigma=2 \pi \int_{0}^{\tau} \mathrm{P}(\mathrm{r}) \mathrm{r} d \mathrm{r}
$$

where $a_{0}$ and $D_{0}$ and $m$ are parameters fitted using the experimental data. The same set of $\mathrm{D}_{0}, \mathrm{a}_{0}$, and $\mathrm{m}$ must, however, describe the chemical damages observed for all the different ions. Assuming that one hit (one electron) can break a bond, $\mathrm{m}$ is taken as equal to 1 . Figure 5 outlines this model.

Table 1 gives some results obtained from the loss of the nitrate functions and the $\mathrm{C}-\mathrm{O}$ bond breaking.

\section{Conclusion}

Table 1 shows the first attempt to describe, with the present model, the experimental chemical cross sections with a target size of $0.2 \mathrm{~nm}$ and $\mathrm{D}_{0}$ values of $2 \times 10^{5} \mathrm{~Gy}$ and $3 \times 10^{5}$ Gy for $\mathrm{C}-\mathrm{O}$ and $\mathrm{N}-\mathrm{O}$ bonds respectively. At this stage any differences in the initial election energy spectra have been neglected. In spite of the use of the very simple calculation of dose $\overline{\mathrm{D}}(\mathrm{r})$, it is surprising to

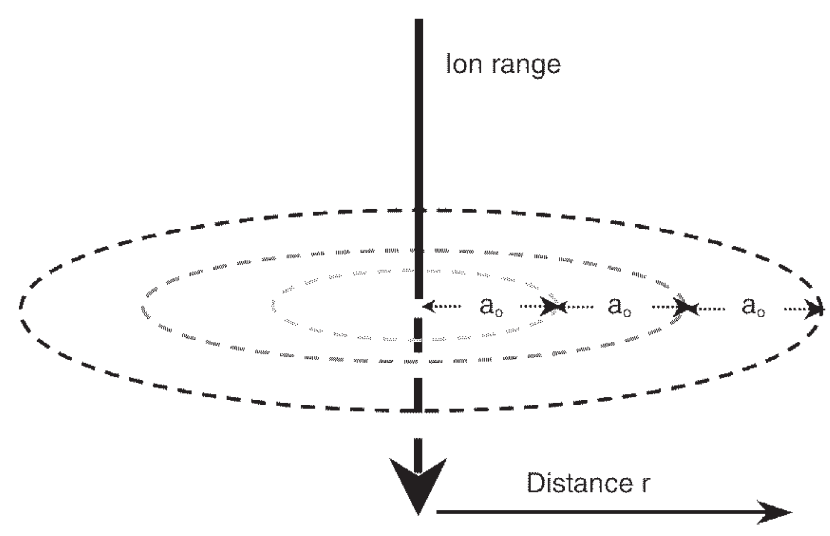

Figure 5. Our model assumptions in calculating the average delta ray dose in ranges of radial distances $a_{0}$.

$$
\sigma=2 \pi\left\{\int_{0}^{\mathrm{a}_{0}} \mathrm{P}(\mathrm{r}) \mathrm{rdr}+\int_{\mathrm{a}_{0}}^{2 \mathrm{a}_{0}} \mathrm{P}(\mathrm{r}) \mathrm{rdr}+\ldots+\int_{\mathrm{na}_{0}}^{\tau} \mathrm{P}(\mathrm{r}) \mathrm{rdr}\right\}
$$

find a reasonable agreement between the experimental and calculated values. However, the model also shows a significantly weaker dependence on ion energy as compared to the experimental observations (see also Figure 1).

\section{References}

1. Barillon, R., Fromm, M., Chambaudet, A., Marah, H., and Sabir, A. Track Etch Velocity in a Radon Detector (LR115, Cellulose Nitrate). Radiat. Meas. 28 (1-6), 619-628 (1997).

2. Brun, C., and 11 others. Intercomparative Study of the Detection Characteristics of the CK-39 SSNTD for Light Ions: Present Status of the Besancon-Dresden Approaches. $\mathrm{Ra}$ diat. Meas. 31 (1-6), 89-89 (1999).

3. Fromm, M., Vaginay, F., Pusset, D., Meesen, G., Chambaudet, A., and Poffijn, A. 3-D Confocal Microscopy of Etched Nuclear Tracks in CR-39. Physica Medica XVII (Suppl. 1), 144-146 (2001).

4. Waligórski, M. P. R., Hamm, R. N., and Katz, R. Radial Distribution of Dose around the Path of a Heavy Ion in Liquid Water. Nucl. Tracks Radiat. Meas. 11 (6), 309-319 (1986).

5. Biersack, J. P., and Ziegler, J. F. Calculation Code TRIM 91 (New York: Pergamon Press) (1991).

6. Benton, E. V., and Nix, W. D. The Restricted Energy Loss Criterion for Registration of Charged Particles in Plastics. Nucl. Instrum. Methods 67, 343-352 (1969).

7. Barillon, R., Fromm, M., Chambaudet, A., Katz, R., Stoquert, J. P., and Pape, A. Bond Scission Cross Sections for $\alpha$-particles in Cellulose Nitrate (LR115). Radiat. Meas. 31, 71-75 (1999).

8. Kovalenko, V. I., Mukhamadeeva, R. M., Maklakova, L. N., and Gustova, N. G. Interpretation of the IR Spectrum and Structure of Cellulose Nitrate. J. Struct. Chem. 31 (4), 540547 (1993). 
9. Katz, R. Cross Section. Appl. Radiat. Isot. 41 (6), 563-567 (1989).

10. Barillon, R., and Katz, R. How to Describe the Chemical Structure of a Latent Track Induced by Light Ions in Plastics Detectors? In: Proc. 1st Int. Symp. on Supercritical Water Cooled Reactors, 406, 1-8, November 6-8, 2000, Tokyo.

11. Katz, R., and Pinkerton, F. E. Response of Nuclear Emulsions to Ionizing Radiations. Nucl. Instrum. Methods 130, 105-119 (1975).

12. Miterev, A. M. Calculation of Track Parameters of Heavy Ions in Amorphous Media. High Energ. Chem. 31 (3), 173178 (1995).
13. Butts, J. J., and Katz, R. Theory of RBE for Heavy Ion Bombardment of Dry Enzymes and Viruses. Radiat. Res. 30, 855871 (1967).

14. Heckman, H. H., Perkins, B. L., Simon, W. B., Smith, F. M., and Barkas, W. H. Ranges and Energy Loss Processes of Heavy Ions in Emulsion. Phys. Rev. 117, 544-556 (1960).

15. Katz, R., Cucinotta, F. A., and Zhang, C. X. The Calculation of Radial Dose from Heavy Ions: Predictions of Biological Action Cross Sections. Nucl. Instrum. Methods Phys. Res. B 107, 287-291 (1996). 